FIGUEIREDO, E.B.; MALHEIROS, E.B.; BRAZ, L.T. Interação genótipo x ambiente em cultivares de alface na região de Jaboticabal. Horticultura Brasileira, Brasília, v.22, n.1, p. 66-71, jan-mar 2004.

\title{
Interação genótipo $x$ ambiente em cultivares de alface na região de Jaboticabal
}

\author{
Eduardo B. de Figueiredo ${ }^{1}$; Euclides B. Malheiros ${ }^{1}$; Leila T. Braz ${ }^{2}$ \\ UNESP, ${ }^{1}$ Depto. Ciências Exatas, ${ }^{2}$ Depto. Produção Vegetal, 14884-900 Jaboticabal-SP; E-mail: eduardobfigueiredo@hotmail.com
}

\section{RESUMO}

Estudou-se a interação genótipo x ambiente de doze cultivares de alface, sendo quatro do grupo lisa (Babá de Verão, Karla, Nacional e Elisa), quatro do grupo crespa (Simpson, Hortência, Verônica e Grand Rapids) e quatro do grupo americana (Laidy, Tainá, Lucy Brown e Raider). Os tratamentos foram constituídos pelo cultivo da alface em dez ambientes (casa de vegetação, túnel baixo de cultivo, túnel baixo com sombrite, agrotêxtil e campo, na presença e ausência de mulching). Foram utilizados dois períodos de cultivo, agosto a novembro de 2001 e março a junho de 2002 em Jaboticabal. Cada experimento (ambiente de cultivo) foi conduzido utilizando-se o delineamento de blocos casualizados, com doze cultivares e três repetições. A análise de variância conjunta demonstrou valores de F significativos $(\mathrm{p}<0,01)$ para a interação genótipo $\mathrm{x}$ ambiente. Para $\mathrm{o}$ cultivo de agosto a novembro/2001, as melhores respostas foram obtidas para as cultivares do Grupo Lisa, nos ambientes casa de vegetação com mulching, túnel baixo de cultivo sem mulching e campo sem mulching. Todas as cultivares apresentaram piores desempenhos nos ambientes túnel com sombrite sem mulching, agrotêxtil com e sem mulching. No cultivo de março a junho/2002, houve maior variabilidade quanto ao comportamento das cultivares avaliadas nos ambientes estudados. Na análise multivariada de agrupamento, a superioridade das cultivares do grupo lisa parece ter sido influenciada pelo número de folhas, tanto para a época 1 , quanto para a época 2. Ressalta-se que, apesar das cultivares do grupo americana apresentarem pior desempenho, as mesmas tiveram os maiores valores de massa seca da parte aérea. Quando se tem como objetivo uma maior produção de alface visando massa seca da parte aérea ou massa fresca da parte aérea, deve-se optar por cultivares do grupo americana, que apresentaram as maiores médias para esta característica. As cultivares do grupo crespa apresentaram as maiores médias para volume de plantas.

Palavras-chave: Lactuca sativa L., sistema de cultivo.

\author{
ABSTRACT \\ Interaction genotype $x$ environment of lettuce cultivars in \\ Jaboticabal, Brazil
}

We evaluated the interaction genotype $\mathrm{x}$ environment of twelve genotypes of lettuce (Babá de Verão, Karla, Nacional, Elisa, Simpson, Hortência, Verônica, Grand Rapids, Laidy, Tainá, Lucy Brown and Raider), cultivated under greenhouse, low tunnel, low tunnel covered with black plastic screen, floating row cover (light-weight woven) and open field. All these treatments were conducted with and without mulching with ten treatments in total. The experiments were conducted in two different periods (August to November, 2001 and March to June, 2002). Each experiment (growth environment) was conducted using randomized blocks and three replicates. The measured variables were dry matter, volume and number of leaves. The value of $F$ was significant $(p<0,01)$ for the interaction genotype $\mathrm{x}$ environment. For the planting period from August to November/ 2001, the best results were obtained with the butterhead cultivars (Babá de Verão, Karla, Nacional, Elisa), cultivated under greenhouse with mulching, low tunnel without mulching and field without mulching. All cultivars had the worst performance when cultivated under tunnel with black plastic screen with or without mulching and floating row cover with or without mulching. For the planting period from March to June/2002, occurred a higher variability for all cultivars under studied environments. In this period, the cultivars of the butterhead group showed the best performance; the worst performance was observed for cultivars of crisphead group, in all environments. As observed for the planting period from August to November/2001, the superiority of butterhead cultivars group could be influenced by the number of leaves. Crisphead cultivars showed the worst results. However, these cultivars obtained the highest values of dry matter. When the goal of production is to obtain dry or fresh matter, the best option are the cultivars Laidy, Tainá, Lucy Brown and Raider, which showed the highest medias. When the final goal is the production of plants with bigger volume, the cultivars Simpson, Hortência, Verônica and Grand Rapids are the more adequate.

Keywords: Lactuca sativa, growth system, cultivars.

\section{(Recebido para publicação em 25 de novembro de 2002 e aceito em 3 de dezembro de 2003)}

\begin{abstract}
$\mathrm{A}$ alface (Lactuca sativa L.) é consi derada a hortaliça folhosa mais importante na alimentação do brasileiro, o que assegura à cultura expressiva importância econômica. Nos últimos anos, a cultura da alface tem experimentado mudanças significativas, tanto em relação às cultivares utilizadas, quanto aos sistemas de produção e formas de comercialização. O volume comercializado na CEAGESP em 2001
\end{abstract}

foi de $17.315 \mathrm{t}$ (Agrianual, 2002), bem abaixo do volume comercializado no ano anterior (21.915 t), demonstrando as transformações que a cultura sofreu em sua forma de comercialização. Os produtores estão preferindo comercializar seus produtos diretamente com as redes de supermercados e feiras livres, de maneira mais ágil, moderna e lucrativa.

O sistema de cultivo protegido, além de propiciar alta qualidade ao produto, permite antecipação da colheita, menor consumo de água e fertilizantes, produção fora de época, melhor preço, maior produtividade e preservação do meio ambiente (Jensen e Collins, 1983; Castellane e Araújo, 1994; Resh, 1997). O cultivo da alface em ambiente protegido reduz significativamente o efeito ambiental provocado por alguns fatores climáticos, como geada, vento, frio, granizo, insolação e chuva demasiada. Ape- 
sar das mudanças micrometeorológicas que ocorrem em condições de cultivo protegido serem responsáveis pelo bom desempenho das culturas (Farias, 1991), nem todas as cultivares se adaptam a esta modalidade. Assim, a escassez de cultivares selecionadas ou melhoradas especificamente para estes ambientes, aliada às temperaturas elevadas durante os meses de verão, têm dificultado a difusão do cultivo protegido entre os olericultores.

Ao contrário do que ocorre com outras culturas como batata, milho e feijão, para a cultura da alface não existe uma rede de ensaios de competição de cultivares abrangendo vários locais, anos e épocas de plantio. Os produtores têm utilizado cultivares recomendadas pelas empresas produtoras de sementes, que nem sempre se adaptam a uma ampla faixa de ambientes (Gualberto, 2000). A adaptação de uma cultivar em ampla extensão de ambientes é considerada de interesse para o produtor, quando se propõe incrementar cultivos. Dificuldades surgem quando cultivares interagem com ambientes, dificultando a interpretação dos resultados. Considerando as diferentes estações climáticas nas quais a alface é cultivada (mesmo em ambiente protegido), é de se esperar a ocorrência de uma elevada interação genótipo x ambiente (Gualberto, 2000).

Com o objetivo de estudar a interação genótipo $\mathrm{x}$ ambiente de doze cultivares de alface em dez ambientes de cultivo em duas épocas, na região de Jaboticabal, desenvolveu-se o presente trabalho.

\section{MATERIAL E MÉTODOS}

O trabalho foi desenvolvido na UNESP, Campus de Jaboticabal, cujas coordenadas são $21^{\circ} 15^{\prime} 22^{\prime}$ ' S, $48^{\circ} 18^{\prime}$ $58^{\prime}$ W e altitude média de $595 \mathrm{~m}$. O clima da região é subtropical, com chuvas no verão e inverno relativamente seco, apresentando precipitação anual média de $1.440 \mathrm{~mm}$, com temperatura média do mês mais quente superior a $22^{\circ} \mathrm{C}$.

As cultivares estudadas foram do grupo lisa (Babá de Verão, Karla, Nacional e Elisa); do grupo crespa (Simpson, Hortência, Verônica e Grand Rapids); do grupo americana (Laidy, Tainá, Lucy
Brown e Raider). As cultivares foram avaliadas em casa de vegetação, túnel baixo, túnel baixo com sombrite, agrotêxtil e em campo, com e sem o uso de mulching, totalizando dez ambientes.

A casa de vegetação utilizada foi do modelo capela com $48 \times 7 \mathrm{~m}$, altura do pé direito de $3,5 \mathrm{~m}$, com as faces laterais e frontais fechadas por tela de sombreamento, com $30 \%$ de interceptação de luz. Os túneis baixos de cultivo foram construídos com arcos de ferro galvanizado cobertos com conduíte plástico, com dimensões de $1,50 \mathrm{~m}$ de altura, $1,20 \mathrm{~m}$ de base e $25 \mathrm{~m}$ de comprimento, com cobertura de polietileno transparente de baixa densidade, $100 \mathrm{~mm}$ de espessura e aditivado anti-UV (ultravioleta). Os túneis cobertos com tela de sombreamento foram construídos com arcos com as dimensões de 1,50 $\mathrm{m}$ de altura, 1,20 $\mathrm{m}$ de base e $25 \mathrm{~m}$ de comprimento, com capacidade de $30 \%$ de atenuação da radiação solar. Nos tratamentos com agrotêxtil: as coberturas foram colocadas diretamente sobre as plantas e fixadas por estacas nas laterais, utilizando o agrotêxtil ("tecido não tecido") com gramatura de $30 \%$, aditivado com filme anti-UV. O cultivo em campo foi feito sem nenhum tipo de cobertura. O plantio das mudas nos tratamentos acima descritos foi feito com e sem o uso de cobertura plástica do solo (mulching). Nos tratamentos com mulching utilizou-se filme de polietileno preto com $25 \mathrm{~mm}$ de espessura.

$\mathrm{O}$ experimento foi conduzido em duas épocas: (1) de agosto a novembro de 2001, caracterizada pela média mensal das temperaturas máximas diárias de agosto, setembro, outubro e novembro de $28,9^{\circ} \mathrm{C} ; 29,7^{\circ} \mathrm{C} ; 30,4^{\circ} \mathrm{C}$; e $30,7^{\circ} \mathrm{C}$, respectivamente; média mensal das temperaturas mínimas diárias de $14^{\circ} \mathrm{C}$; $16,4^{\circ} \mathrm{C} ; 17,8^{\circ} \mathrm{C}$ e $19,8^{\circ} \mathrm{C}$, e precipitação acumulada de $61 \mathrm{~mm} ; 27,3 \mathrm{~mm}, 149,3$ mm e $222,7 \mathrm{~mm}$. (2) de março a junho de 2002, caracterizada pela média mensal das temperaturas máximas diárias dos meses de março, abril, maio e junho de $31,8^{\circ} \mathrm{C} ; 32,0^{\circ} \mathrm{C} ; 28,2^{\circ} \mathrm{C}$ e $29,1^{\circ} \mathrm{C}$, respectivamente; média mensal das temperaturas mínimas diárias $19,8^{\circ} \mathrm{C}$; $18,2^{\circ} \mathrm{C} ; 15,7^{\circ} \mathrm{C}$ e $14,5^{\circ} \mathrm{C}$, e precipitação acumulada de $146 \mathrm{~mm} ; 5 \mathrm{~mm} ; 45,8 \mathrm{~mm}$ e $0 \mathrm{~mm}$.
O experimento foi conduzido no delineamento em blocos casualizados, com doze cultivares e três repetições. $\mathrm{O}$ fator bloco foi considerado com efeito aleatório e os demais fatores com efeitos fixos. Cada unidade experimental foi constituída de quatro linhas de $1,8 \mathrm{~m}$, espaçadas de $0,3 \mathrm{~m}$. Foram utilizadas seis plantas por linha, totalizando 24 plantas por parcela.

Para os ambientes em campo, o preparo do solo foi realizado com uma aração na profundidade de $0,35 \mathrm{~m}$, seguida de uma gradagem niveladora. Posteriormente, foi realizado o preparo dos canteiros com rotoencanteirador, nas dimensões de 1,2x25 m, distanciados de $0,4 \mathrm{~m}$, orientados no sentido leste-oeste. Para os ambientes de cultivo protegido, o preparo do solo foi realizado utilizando-se enxada rotativa, e os canteiros, nas mesmas dimensões usadas nos ambientes anteriores, foram preparados manualmente. A calagem e adubação de plantio foram realizadas obedecendo às recomendações de Trani et al. (1996) para alface no estado de São Paulo. As mudas foram produzidas em bandejas de poliestireno expandido com 288 células, contendo substrato comercial recomendado para hortaliças folhosas. $\mathrm{O}$ transplante ocorreu quando as mudas atingiram quatro ou cinco folhas definitivas, cerca de 28 a 35 dias, de acordo com a época de cultivo.

Foi utilizado o sistema de irrigação por gotejamento com uma linha de tubos gotejadores para cada linha de plantio. O espaçamento entre gotejadores foi de $0,3 \mathrm{~m}$. A freqüência e o volume de água aplicados em cada experimento foram determinados através de critérios visuais diversos, tais como fase de desenvolvimento das plantas e condições climáticas.

As colheitas foram efetuadas de acordo com as características de cada grupo de cultivares, em função da idade da planta e época de plantio. Nos grupos de experimentos realizados na primeira época, as cultivares dos grupos crespa e lisa foram colhidas aos 71 dias após a semeadura, e as cultivares do grupo americana aos 78 dias após a semeadura. Nos grupos de experimentos realizados na segunda época, as alfaces dos grupos crespa e lisa foram colhidas aos 
Tabela 1. Grupos de ambientes, em cultivares de alface, na região de Jaboticabal, obtidos pelos índices de dissimilaridade, por caráter avaliado, em duas épocas. Jaboticabal, UNESP, 2001.

\begin{tabular}{|c|c|c|c|c|c|c|}
\hline \multirow{3}{*}{ Época ${ }^{3}$} & \multicolumn{6}{|c|}{ Caráter $^{1}$} \\
\hline & \multicolumn{2}{|r|}{ MSPA } & \multicolumn{2}{|r|}{ VOL } & \multicolumn{2}{|r|}{ NF } \\
\hline & Grupos & Ambiente2 & Grupos & Ambiente & Grupo & Ambiente \\
\hline \multirow{4}{*}{1} & G1 & $1,5,6$ & G1 & $2,5,6,7,8,9,10$ & G1 & $1,2,4,5,6,8,10$ \\
\hline & G2 & $3,4,7$ & G2 & 3,4 & G2 & $3,7,9$ \\
\hline & G3 & $2,9,10$ & G3 & 1 & & \\
\hline & G4 & 8 & & & & \\
\hline \multirow{3}{*}{2} & $\mathrm{G} 1$ & $1,2,3,5,6,8$ & $\mathrm{G} 1$ & $1,2,3,5,6,7,8,9$ & G1 & $3,5,6,9,10$ \\
\hline & $\mathrm{G} 2$ & 4,7 & $\mathrm{G} 2$ & 4 & G2 & $1,2,4,8$ \\
\hline & G3 & 9,10 & G3 & 10 & G3 & 7 \\
\hline
\end{tabular}

${ }^{1}$ MSPA - Massa seca da parte aérea; VOL - Volume de planta; NF - Número de folhas. ${ }^{2}: 1$ e 2 - casa de vegetação com e sem mulching, 3 e 4 - túnel baixo de cultivo com e sem mulching, 5 e 6 - túnel baixo com sombrite com e sem mulching, 7 e 8 - agrotêxtil com e sem mulching, 9 e 10 - campo com e sem mulching. ${ }^{3}$ : 1- agosto a novembro de 2001; 2- março a junho de 2002).

78 dias após a semeadura e as do grupo americana aos 85 dias após a semeadura.

Avaliou-se (a) massa fresca da parte aérea (g/planta) (MFPA), obtida a partir de cinco plantas por parcela e colhidas pela manhã; (b) massa seca da parte aérea (g/planta) (MSPA), obtida a partir de duas plantas secas em estufa com circulação forçada de ar a $65^{\circ} \mathrm{C}$ até atingirem peso constante; (c) diâmetro médio e altura de planta (cm) (DM e ALT), sendo que para obtenção do diâmetro médio, feito um dia antes da colheita foram coletados os dados referentes ao diâmetro maior (d1), diâmetro menor (d2) e altura (h) de duas plantas por parcela, utilizando-se régua graduada; e (d) volume de plantas $\left(\mathrm{cm}^{3} /\right.$ planta) (VOL), sendo que a partir dos diâmetros e altura, obteve-se a estimativa do volume da planta utilizando-se a fórmula da metade do volume de uma elipsóide de diâmetros $\mathrm{d} 1 \mathrm{e} \mathrm{d} 2$ e altura $\mathrm{h}$, ou seja: $\mathrm{V}=4$ / $3 \mathrm{p}\left(\mathrm{d}_{1} / 2\right)\left(\mathrm{d}_{2} / 2\right) \mathrm{h}$; e) número de folhas por planta (NF). Nesta contagem, foram consideradas apenas as folhas que atingiram o comprimento mínimo de $1,5 \mathrm{~cm}$.

Para avaliar a existência de variabilidade genética entre as cultivares estudadas, a precisão relativa de cada experimento e a homogeneidade das variâncias, realizou-se a análise univariada, por ambiente e época. A análise de variância conjunta foi realizada considerando os 10 ambientes e as duas épocas, sendo, efeito aleatório para blocos e para as demais fontes de variação. A seguir foi realizada a análise de variância conjunta, considerando os 10 ambientes, em cada época.

Utilizou-se o método de agrupamento de ambientes com base no algoritmo de Lin (1982), citado por Cruz e Regazzi (2001), que consiste em estimar a soma de quadrados para a interação entre cultivares e agrupar aqueles ambientes cuja interação é não significativa.

Para agrupar cultivares e ambientes similares, utilizou-se análise de agrupamento multivariada (Análise de "Cluster"), utilizando-se o programa SAS (Statistics Analysis System). Como coeficiente de dissimilaridade foi utilizada a distância Euclidiana, e como estratégia de agrupamento utilizou-se o método de agrupamento não ponderado aos pares.

\section{RESULTADOS E DISCUSSÃO}

Pelos valores dos coeficientes de correlação, as características MSPA e MFPA foram correlacionadas $\left(\mathrm{r}^{3} 0,70 \mathrm{e}\right.$ $\mathrm{p}<0,01)$, bem como VOL com DM e ALT. Portanto, apenas MSPA, VOL e NF foram abordadas neste estudo.

As análises de variância individuais para MSPA, VOL e NF, dentro de cada ambiente, em cada época, tiveram como principal objetivo estimar a variância residual de cada ensaio, para verificar os ambientes que poderiam ser considerados homogêneos, segundo os critérios sugeridos por Cruz e Regazzi (2001), permitindo a realização da análise conjunta com todos os ambientes.
Os resultados da análise de variância conjunta (Tabela 1), envolvendo cultivares, ambientes e épocas, para MSPA, VOL e NF, demonstraram valores de F significativos $(p<0,01)$ para todas as interações envolvendo o fator época (ExC, AxC, ExA, ExAxC). Na Figura 1 pode-se observar para NF que, apesar da interação, existe uma destacada superioridade das cultivares do grupo lisa sobre as outras cultivares, independentemente da época, para a grande maioria dos ambientes.

Considerando-se as cultivares dos grupos crespa e americana, observa-se uma certa superioridade do número de folhas das cultivares do grupo americana sobre as do grupo crespa, para a segunda época, o que não acontece para a primeira época (Figura 1). Streck et al. (1994), em Santa Maria (RS), verificaram maiores valores no número de folhas para duas cultivares de alface (lisa White Boston e crespa Hampson), sob túnel baixo no inverno e na primavera, comparadas ao cultivo em ambiente externo. Segovia (1991), durante o inverno de Santa Maria, comparou três cultivares de alface em ambiente natural e sob estufa plástica, verificando aumento significativo no número de folhas ao longo de todo o período avaliado para o cultivo em estufa, e caracterizando uma maior atividade metabólica, com menor intervalo de dias para emissão de novas folhas.

Para MSPA observa-se de maneira geral, independente do ambiente e da 
Tabela 2. Análise multivariada do agrupamento de cultivares de alface e ambientes, considerando-se simultaneamente massa seca da parte aérea (MSPA), volume de planta (VOL) e número de folhas (NF), em duas Épocas [(1) agosto a novembro de 2001; (2)março a junho de 2002], na região de Jaboticabal. Jaboticabal, UNESP, 2001.

\begin{tabular}{|c|c|c|c|c|c|c|c|c|c|c|c|}
\hline \multirow{2}{*}{ Época } & \multirow{2}{*}{ Grupo } & \multicolumn{10}{|c|}{ Ambiente } \\
\hline & & 1 & 2 & 3 & 4 & 5 & 6 & 7 & 8 & 9 & 10 \\
\hline \multirow{7}{*}{1} & G1 & $1,2,3,4$ & $2,3,4$ & & $1,2,3,4$ & 1,2 & & & & & $1,2,3,4$ \\
\hline & G2 & 6,7 & & & $6,7,8$ & & & & & & \\
\hline & G3 & 5,8 & $5,6,7,8$ & $6,7,8$ & 5 & $5,6,7,8$ & & & & & \\
\hline & G4 & $\begin{array}{l}9,10 \\
11,12\end{array}$ & $\begin{array}{l}9,10,11 \\
12\end{array}$ & $\begin{array}{l}9,10,11 \\
12\end{array}$ & $9,10,11$ & $\begin{array}{l}9,10,11, \\
12\end{array}$ & 11 & & 6 & $\begin{array}{l}6,9,10 \\
11\end{array}$ & $5,6,7,8$ \\
\hline & G5 & & & & 12 & & & & & 12 & $\begin{array}{l}9,10,11, \\
12\end{array}$ \\
\hline & G6 & & 1 & $1,2,3,4$ & & 3,4 & $1,2,3,4$ & $\begin{array}{l}1,2,3,4 \\
8\end{array}$ & $1,2,3,4$ & $1,2,3,4$ & \\
\hline & $\mathrm{G} 7$ & & & 5 & & & $\begin{array}{l}5,6,7,8 \\
9,10,12\end{array}$ & $\begin{array}{l}5,6,7,9 \\
10,11 \\
12\end{array}$ & $\begin{array}{l}5,7,8,9 \\
10,11 \\
12\end{array}$ & $5,7,8$ & \\
\hline \multirow{8}{*}{2} & G1 & $1,3,4$ & $1,2,3,4$ & & 1 & $1,2,3,4$ & $2,3,4$ & $2,3,4$ & $\begin{array}{l}1,2,3 \\
4\end{array}$ & $2,3,4$ & $2,3,4$ \\
\hline & G2 & & & $1,2,3,4$ & $2,3,4$ & & 1 & & & 1 & 1 \\
\hline & G3 & 2 & & & & & & 1 & & & \\
\hline & G4 & 5 & 5 & 5 & 5,7 & 5,8 & & $5,6,7,8$ & & & \\
\hline & G5 & 8 & 6,8 & 8 & 6,8 & 6,7 & 5,8 & & $5,6,7,8$ & & \\
\hline & G6 & 6,7 & & 6,7 & & & 6,7 & & & 7,8 & 6,7 \\
\hline & $\mathrm{G} 7$ & 11,12 & $\begin{array}{l}7,10,11, \\
12\end{array}$ & $\begin{array}{l}9,10,11 \\
12\end{array}$ & $\begin{array}{l}9,10 \\
11,12\end{array}$ & $\begin{array}{l}9,10,11, \\
12\end{array}$ & $\begin{array}{l}9,10,11 \\
12\end{array}$ & & $\begin{array}{l}9,10,11 \\
12\end{array}$ & 5,6 & $10,5,8$ \\
\hline & G8 & 9,10 & 9 & & & & & $\begin{array}{l}9,10,11 \\
12\end{array}$ & & $\begin{array}{l}9,10,11, \\
12\end{array}$ & $9,11,12$ \\
\hline
\end{tabular}

Cultivares (1-Babá de Verão, 2-Karla, 3-Nacional, 4-Elisa, 5-Simpson, 6-Hortência, 7-Verônica, 8-Grand Rapids, 9-Laidy, 10-Tainá, 11Lucy Brown e 12-Raider); ambientes: 1 e 2 - casa de vegetação com e sem mulching, 3 e 4 - túnel baixo de cultivo com e sem mulching, 5 e 6 - túnel baixo com sombrite com e sem mulching, 7 e 8 - agrotêxtil com e sem mulching, 9 e 10 - campo com e sem mulching.

época, que as cultivares do grupo americana apresentam os maiores valores comparados com os demais grupos e que as cultivares do grupo lisa apresentam os menores valores.

Para VOL, observa-se que, independente do ambiente e da época estudada, as cultivares do grupo crespa apresentam maiores volumes que as demais cultivares, e as que apresentam menores volumes são as do grupo americana. Com estes resultados fica evidente que as vantagens de algumas cultivares sobre outras dependem da característica considerada. Devido ao alto nível de significância das interações de cultivares e ambientes com o fator época $(\mathrm{p}<0,01)$, apresenta-se o estudo da interação genótipo $\mathrm{x}$ ambiente dentro de cada época (Tabela 2).

Observa-se interação significativa $(\mathrm{p}<0,01)$, entre genótipo $\mathrm{x}$ ambiente, para os três caracteres estudados, nas duas épocas (Tabela 2).

Para identificar se existem, entre os ambientes estudados, padrões de similaridade de respostas de cultivares, realizou-se o agrupamento de ambientes pelo método de Lin (1982), que consiste em estimar a soma de quadrados para a interação entre genótipos e pares de ambientes e, posteriormente, agrupar aqueles ambientes cuja interação é não significativa. $\mathrm{O}$ método prossegue com a estimativa da soma de quadrados entre genótipos e grupos de três ambientes, quatro, e assim por diante, até obter os grupos com mesmo padrão de similaridade.

Os grupos de ambientes, obtidos pelos índices de dissimilaridade, por variável e por época, são apresentados na Tabela 1. Observou-se que, para MSPA, os ambientes casa de vegetação com mulching, túnel baixo com sombrite e com mulching e túnel com sombrite sem mulching, apresentaram similaridade para todas as épocas estudadas. O mesmo foi observado para o grupo de ambientes onde se utilizou o túnel baixo de cultivo sem mulching e agrotêxtil 


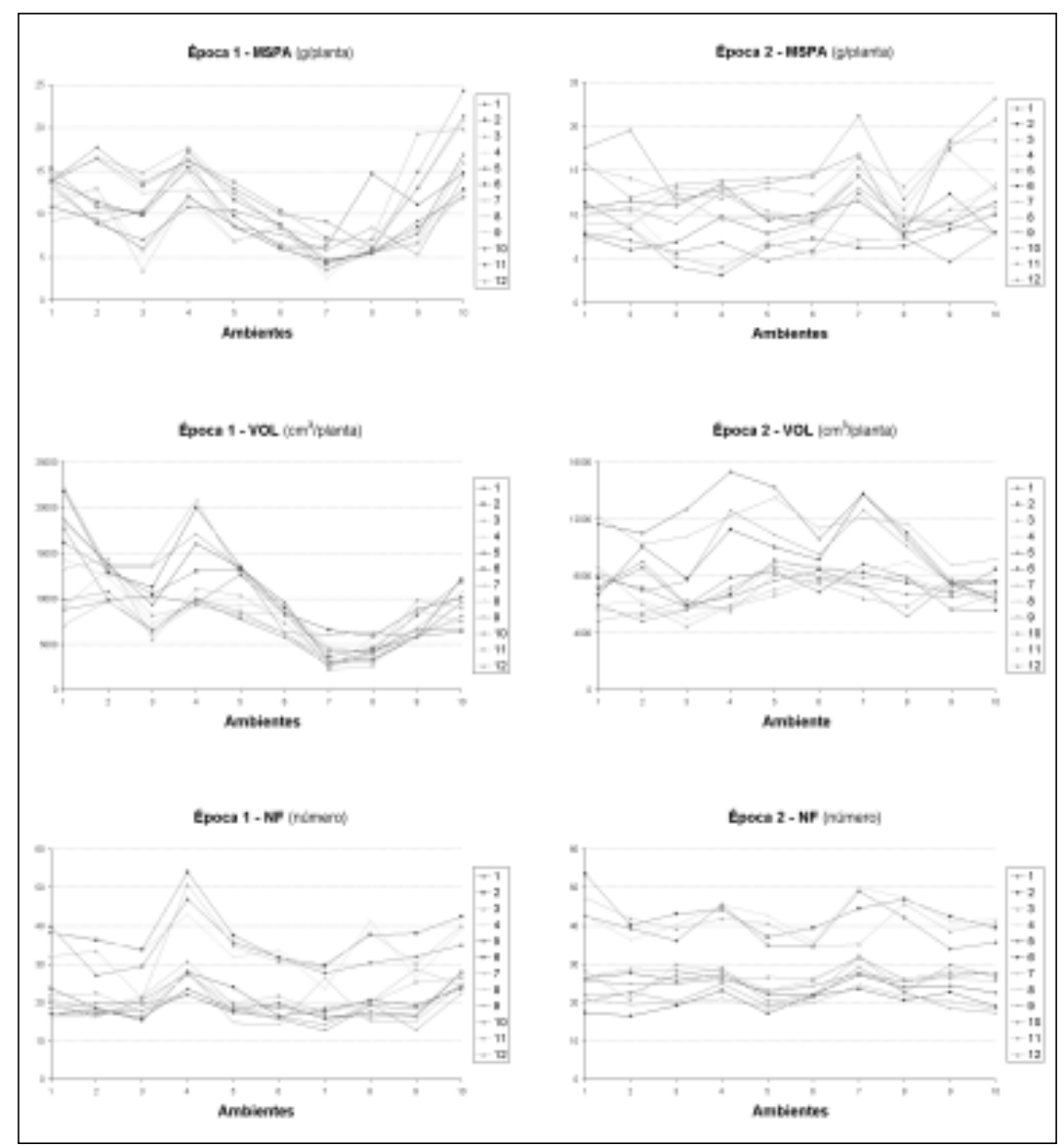

Figura 1.Representação da massa seca da parte aérea (MSPA), volume (VOL) e número de folhas (NF) para as cultivares (1-Babá de Verão, 2-Karla, 3-Nacional, 4-Elisa, 5-Simpson, 6-Hortência, 7-Verônica, 8-Grand Rapids, 9-Laidy, 10-Tainá, 11-Lucy Brown e 12-Raider), nos ambientes: 1 e 2 (casa de vegetação com e sem mulching), 3 e 4 (túnel baixo de cultivo com e sem mulching), 5 e 6 (túnel baixo com sombrite com e sem mulching), 7 e 8 (agrotêxtil com e sem mulching), 9 e 10 (campo com e sem mulching), nas épocas (1- agosto a novembro de 2001; 2- março a junho de 2002). Jaboticabal, UNESP, 2001.

com mulching e para o grupo de ambientes campo com mulching e campo sem mulching. Os ambientes em casa de vegetação sem mulching e túnel baixo de cultivo com mulching apresentam similaridade com alguns ambientes em uma das épocas estudadas e com outros na outra época. Ressalta-se que o ambiente com agrotêxtil sem mulching não apresentou similaridade com qualquer outro ambiente na primeira época.

Para a variável VOL, observou-se que os ambientes casa de vegetação sem mulching, túnel baixo com sombrite com mulching, túnel baixo com sombrite sem mulching, agrotêxtil com mulching, agrotêxtil sem mulching e campo com mulching apresentaram-se similares nas duas épocas estudadas. $\mathrm{O}$ ambiente cam- po sem mulching apresenta similaridade com alguns ambientes na primeira época e não apresenta qualquer similaridade com outros ambientes na segunda época. Os ambientes casa de vegetação com mulching, túnel baixo com mulching e túnel baixo sem mulching não apresentam similaridade com outros ambientes nas épocas estudadas.

Para a variável NF, observou-se que os ambientes casa de vegetação com mulching, casa de vegetação sem mulching, túnel baixo sem mulching e agrotêxtil sem mulching apresentam similaridade nas duas épocas estudadas; bem como o grupo de ambientes túnel baixo com sombrite com mulching, túnel baixo com sombrite sem mulching e campo sem mulching; e o grupo túnel baixo com mulching e campo com mulching. $\mathrm{O}$ ambiente agrotêxtil com mulching apresentou similaridade com alguns ambientes na primeira época $\mathrm{e}$ não apresentou similaridade na segunda época.

Destaca-se que, entre os ambientes estudados, apenas os ambientes túnel baixo com sombrite com mulching e túnel baixo com sombrite sem mulching apresentam-se similares para todas as características estudadas em todas as épocas.

Tendo em vista a variabilidade de grupos similares por variável, realizouse a análise multivariada de agrupamento, considerando-se simultaneamente as três características e as duas épocas. Os resultados da análise de agrupamento (Tabela 2), mostraram que, para a primeira época, os melhores grupos de cultivares concentram-se nos ambientes casa de vegetação com mulching, casa de vegetação sem mulching, túnel baixo sem mulching, túnel baixo com sombrite com mulching e campo sem mulching; os piores nos ambientes, túnel baixo com sombrite sem mulching, agrotêxtil com mulching e agrotêxtil sem mulching e, para o ambiente campo com mulching, as cultivares apresentam uma grande variação no desempenho.

As melhores respostas, para a primeira época, foram obtidas pelas cultivares Babá de Verão, Karla, Nacional e Elisa, nos ambientes casa de vegetação com mulching, túnel baixo sem mulching e campo sem mulching e as cultivares Karla, Nacional e Elisa no ambiente casa de vegetação sem mulching e as cultivares Babá de Verão e Karla no ambiente túnel baixo com sombrite com mulching, seguidas pelas cultivares Simpson, Hortência, Verônica e Grand Rapids nos ambientes casa de vegetação com mulching, casa de vegetação sem mulching, túnel com mulching, túnel baixo sem mulching e túnel baixo com sombrite com mulching.

Todas as cultivares apresentaram pior desempenho nos ambientes túnel baixo com sombrite sem mulching, agrotêxtil com mulching e agrotêxtil sem mulching com exceção das cultivares Hortência e Lucy Brown, que apresentaram um desempenho interme- 
diário nos ambientes agrotêxtil sem mulching e túnel baixo com sombrite sem mulching, respectivamente.

Ressalta-se que as cultivares do grupo lisa apresentaram-se entre as melhores em todos os ambientes, com exceção para os ambientes túnel baixo com mulching, túnel baixo com sombrite com mulching e campo com mulching. Pelas análises univariadas apresentadas anteriormente, esta vantagem parece ser influenciada pelo maior número de folhas destas cultivares, quando comparadas às demais, em todos os ambientes.

O bom desempenho das cultivares Simpson, Hortência, Verônica e Grand Rapids nos ambientes casa de vegetação com mulching, casa de vegetação sem mulching, túnel baixo com mulching, túnel baixo sem mulching e túnel baixo com sombrite com mulching; parece ser influenciado pelo volume, o que pode ser observado na Figura 1.

Para a segunda época, houve maior variabilidade quanto ao desempenho das cultivares dos três grupos, nos ambientes estudados. Nessa época, as cultivares do grupo lisa apresentaram os melhores desempenhos; as do grupo crespa, apresentaram um desempenho intermediário, e as do grupo americana apresentaram, pior desempenho, para todos os ambientes estudados, considerandose os três caracteres avaliados.

Da mesma forma que para a primeira época, na segunda época, a superioridade das cultivares do grupo lisa parece ter sido influenciada pelo caráter NF. Ressalta-se que, apesar das cultivares do grupo americana apresentarem pior desempenho, verifica-se nas análises univariadas (Figura 1), que são as cultivares que apresentam os maiores valores de MSPA.
Podemos destacar que, para a escolha de uma determinada cultivar para plantio, deve-se observar o mercado e o modo de comercialização de cada região. Quando se tem como objetivo maior produção de alface baseada na MFPA (ou MSPA), deve-se optar por cultivares do grupo americana, que apresentaram maiores valores de MSPA em relação às demais, com exceção da cultivar Karla, nos ambientes casa de vegetação, com e sem mulching, túnel baixo de cultivo, com e sem mulching, e campo aberto, com e sem mulching, (primeira época). Para a segunda época, todas as cultivares do grupo americana foram superiores às demais, em todos os ambientes estudados, apresentando as maiores médias e demonstrando não haver necessidade de maiores investimentos em ambientes modificados.

Quando o objetivo final da produção é a obtenção de plantas com maior volume, visando a comercialização direta com redes de supermercados ou feiras livres, onde se considera o volume de plantas para se preparar os maços, devemos observar que as cultivares do grupo crespa (Figura 1), apresentam as maiores médias para a primeira época, nos ambientes casa de vegetação com mulching, casa de vegetação sem mulching, túnel baixo com mulching, túnel baixo sem mulching e túnel baixo com sombrite com mulching, demonstrando que os túneis baixos de cultivo podem ser utilizados, com menor custo e resultados equivalentes. Para a segunda época, as maiores médias foram obtidas pelas cultivares Simpson, Hortência, Verônica e Grand Rapids, nos ambientes casa de vegetação com mulching, casa de vegetação sem mulching, túnel baixo com mulching, túnel baixo sem mulching, túnel baixo com sombrite com mulching, túnel bai- xo com sombrite sem mulching, agrotêxtil com mulching e agrotêxtil sem mulching; demonstrando uma melhor resposta das cultivares aos ambientes modificados, em relação ao campo aberto.

Contudo, a escolha de cultivares do grupo lisa devem ser de acordo com as exigências de mercado, quanto a qualidade e preferência do tipo de planta ou folha.

\section{LITERATURA CITADA}

AGRIANUAL. São Paulo: FNP, 2002. p.161-162. CASTELLANE, P.D.; ARAÚJO, J.A.C. Cultivo sem solo: hidroponia. Jaboticabal: FUNEP/ UNESP, 1994. $43 \mathrm{p}$.

CRUZ, C.D.; REGAZZI, A.J. Modelos biométricos aplicados ao melhoramento genético. Viçosa: Imprensa Universitária, 2001. 390 p. FARIAS, J.R.B. Respostas do feijão-vagem à disponibilidade hídríca associada a alterações micrometeorológicas em estufa plástica. Porto Alegre: UFRGS, 1991. 177 p. (Tese doutorado). GUALBERTO, R. Adaptabilidade e estabilidade em cultivares de alface (Lactuca sativa $L$.). Jaboticabal: FCAV/UNESP, 2000. 58p. (Projeto de tese).

JENSEN, M.H.; COLLINS, W.L. Hidroponic vegetable production. Horticultural of Plant Nutrition, v.5, p.483-558, 1983.

LIN, C.S. Grouping genotypes by a cluster method directly related to genotype-environment interaction mean square. Theoretical and Applied Genetics, v.62, p.277-280, 1982.

RESH, H.M. Cultivos hidropônicos; nuevas técnicas de producción. 4.ed. Madrid: Mundi-Prensa, 1997. 378p.

SEGOVIA, J.F.O. Influência da proteção ambiental de uma estufa de polietileno transparente sobre o cultivo da alface. Santa Maria: UFSM, 1991.72 p. (Tese mestrado).

STREK, N.A.; BURIOL, G.A.; ANDRIOLO, J.L. Crescimento da alface em túneis baixos com filme de polietileno perfurado. Ciência Rural, Santa Maria, v.24, n.2, p.235-240, 1994.

TRANI, P.E.; PASSOS, F.A.; AZEVEDO FILHO, J.A. Alface, almeirão, chicória, escarola, rúcula e agrião d'água. In: RAIJ, B. Van et al. Recomendações de adubação e calagem para o estado de São Paulo. 2.ed. Campinas: Instituto Agronômico \& Fundação IAC, 1996. p.168-169. (Boletim técnico, 100). 